\title{
Effect of warm pre-stress on highly irradiated pressure vessel steel
}

\author{
Dominique Moinereau ${ }^{1}$, Caroline Landron ${ }^{1}$, Malik Ait-Bachir ${ }^{1}$, Eric Molinié ${ }^{2}$ Eric Garbay ${ }^{2}$ \\ ${ }^{1}$ EDF R\&D, 77818 Moret-sur-Loing, France (Dominique.moinereau@edf.fr) \\ ${ }^{2}$ EDF CEIDRE, 37420 Avoine, France
}

\begin{abstract}
The effect of warm pre-stress (WPS) is well known on cleavage fracture resistance of ferritic steels and has been confirmed on numerous tests on non irradiated materials. Theoritical knowledge let expect that this effect occurs by the same way on irradiated material but has to be demonstrated with experiments in such conditions. An experimental program has been conducted by EDF in Chinon hot cell laboratory on two RPV steels irradiated up to a fluence of $6,5 \cdot 10^{19} \mathrm{n} / \mathrm{cm}^{2}$.

The $1 / 2$ TCT specimens (CT12.5) used in this programme have been irradiated in the capsules of the EDF RPV surveillance program of two PWR reactors. Different types of WPS loading path have been applied to cover typical postulated accidental transients. The results confirmed the effect on WPS on the cleavage fracture resistance of the irradiated materials. No fracture occurred during the cooling phase of the loading path and the fracture toughness values are higher than that measured with conventional isothermal tests.

The analyses of the experiments have been conducted based on use of simplified engineering models and more refined fracture models based on local approach to cleavage fracture. These analyses are in agreement with the experimental results.
\end{abstract}

\section{INTRODUCTION}

Justification of in-service integrity of Reactor Pressure Vessel (RPV) for lifetime design is presented in regular documents, periodically revised and transmitted to French safety authorities for acceptation. In the scope to prepare future, numerous actions have been engaged by EDF since 2002 to gather necessary elements for constituting a RPV irradiated area justification document beyond 40 years, referring a 60 years life assessment. In the field of mechanics, engaged actions must enable to propose new validated methodologies in the aim to improve existing margins for RPV integrity justifications. These methodologies mainly concern two aspects, crack initiation and crack arrest in the brittle or brittle to ductile fracture domain.

The warm pre-stress (WPS) is one of the retained possibilities to improve initiation defect analysis methods. It has been demonstrated that mechanical stresses applied at high temperature at the beginning of a transient can lead to a beneficial effect on pre-existing flaw, avoiding or delaying crack initiation. Indeed, if an hypothetical accidental transient (LOCA or SBLOCA type) occurs, RPV is submitted to a thermo-mechanical loading including the following steps (Figure 1) :

- A mechanical loading first step at high temperature $T_{1}$ (ductile domain), called warm pre-stress (WPS),

- A decreasing step during temperature cooling,

- A possible step of re-loading in the brittle or brittle to ductile transition temperature domain at a temperature $T_{2}$, when specific transients include a main primary loop over pressurization.

In the comparison $\mathrm{K}_{\mathrm{J}}-\mathrm{K}_{1 \mathrm{c}}$, several configurations can be encountered to illustrate the warm pre-stress and its potential interest. The interest of these effects (increasing of margins) is obvious on a RPV integrity analysis opposite to brittle fracture with following phenomena taken into account : 


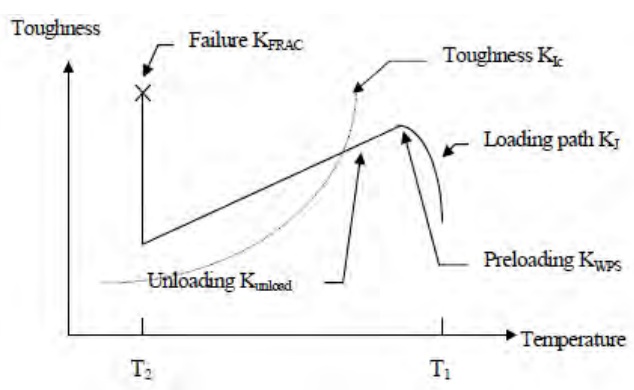

Figure 1. Warm pre-stress principle.

- No possibility to obtain crack initiation during stress intensity factor $K_{J}$ decreasing step

- Effective increasing of $\mathrm{K}_{1 \mathrm{c}}$ toughness when structure will be previously pre-loaded

Beneficial effects of WPS on fracture toughness can be attributed to combination of several phenomena such as crack tip blunting, presence of compressive residual stresses due to pre-loading, hardening of material and necessity to have a plastic strain increment for cleavage crack initiation.

Numerous tests, on CT specimens machined from 16MND5 and 18MND5 non irradiated RPV steels have been performed with several load paths, representative of postulated accidental PTS transients. Results have demonstrated the absence of crack initiation during decreasing step and increasing of effective fracture toughness after warm pre-stress [1][2][3].

EDF Chinon nuclear facilities, in relationship with EDF R\&D, has conducted an experimental program to check WPS effect on irradiated materials representative of RPV steels. A test campaign has been performed on representative RPV steels, irradiated up to a $6,5.10^{19} \mathrm{n} / \mathrm{cm}^{2}$ fluence, corresponding to a 40 equivalent years of operation for reactor pressure vessel. This paper describes the experimental program performed, after selection of materials representative of RPV steels. Initial fracture toughness for selected materials have been consolidated with Master Curve approach. Selection of loading paths, conditions of tests and results obtained are presented. Experimental results are analysed and compared with several analytical WPS engineering models.

\section{EXPERIMENTAL PROGRAM}

\section{Selection of RPV materials}

Failure occurs when the stress intensity factor $\mathrm{K}_{\mathrm{J}}$ at the crack tip reaches the fracture toughness value of the material, $\mathrm{K}_{1 \mathrm{c}}$, or for elastic-plastic failure, $\mathrm{K}_{\mathrm{Jc}}$. Using the ASTM E1921 standard [4], the evaluation of the elastic-plastic fracture toughness $\mathrm{K}_{\mathrm{Jc}}$ with temperature can be derived from the Master Curve approach [4][5]. In practice, this approach is based on the experimental determination of a reference temperature $T_{0}$, which corresponds to a mean fracture toughness of $100 \mathrm{MPa} \cdot \mathrm{m}^{1 / 2}\left(\mathrm{~K}_{\mathrm{Jc}}\right)$ for $1 \mathrm{~T}$ size specimens (1TCT specimen with thickness $B=25.4 \mathrm{~mm}$ ) [4]. This approach allows the determination of the failure probability evolution with temperature, using generally the $5 \%$ (lower bound), 50\% (medium curve) and 95\% (upper bound) fractiles.

Within the framework of this program, it was decided to take $1 / 2$ TCT compact tension specimens (CT12.5 specimens) machined from bending test rods (see Figure 2) coming from EDF RPV irradiation surveillance program. The choice of selected materials was based on the following criteria :

- the vessel material surveillance capsules should have a fluence corresponding to 40 operating years,

- $\mathrm{T}_{0}$ should have been measured with enough valid tests to be confident on the value

- tensile test specimens must be available

- embrittlement kinetics of the material should not be atypical (too low or too high) 
- the chemical composition of the material should be average

Based on these criteria, specimens have been taken from 2 different surveillance capsules (coming from 2 plants referenced Plant $1 \&$ Plant 2):

- $\quad 12$ CT12.5 specimens ( $1 / 2$ TCT), machined from each of 2 bending test rods

- 4 cylindrical tensile test specimens $(6.35 \mathrm{~mm}$ diameter $)$
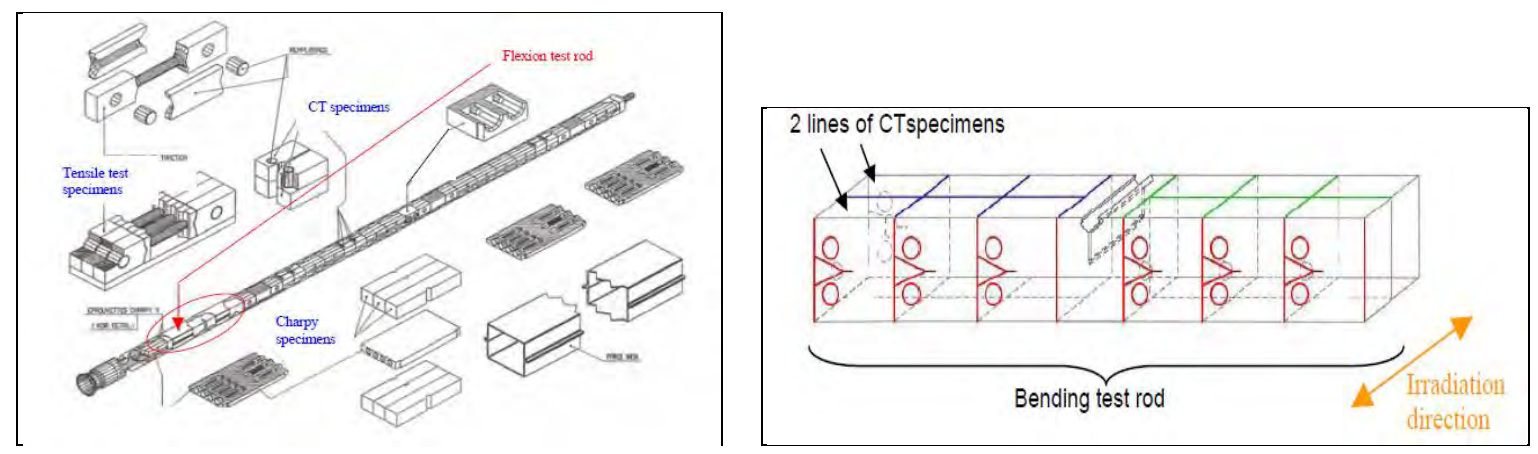

Figure 2. Material surveillance capsule and CT12.5 specimens taken from bending test rod.

The positioning of the surveillance capsules in vessels compared with the irradiation direction makes fluence be different between the 2 sides of the bending rod. So the 2 lines of CT specimens machined from a rod have different fluencies, summarized in Table 1 :

Table 1. Fluence of the specimens.

\begin{tabular}{|c|c|c|}
\hline & Specimens & $\begin{array}{c}\text { Fluence } \\
\left(10^{19} \mathrm{n} / \mathrm{cm}^{2}\right)\end{array}$ \\
\hline \multirow{4}{*}{ CT specimens } & $\begin{array}{c}\text { Plants 1 and 2 CT 1 to 6 } \\
\left(1^{\text {st }} \text { line }\right)\end{array}$ & Fluence A : 6.5 \\
\cline { 2 - 3 } & $\begin{array}{c}\text { Plants 1 and 2 CT 7 to 12 } \\
\left(2^{\text {nd }} \text { line }\right)\end{array}$ & Fluence B : 5.0 \\
\hline \multirow{3}{*}{ Tensile specimens } & Plant 1 B42 & 6.05 \\
\cline { 2 - 3 } & Plant 1 B43 & 5.93 \\
\cline { 2 - 3 } & Plant 2 B47 & 5.96 \\
\hline
\end{tabular}

Due to this difference of fluence, a correction (shift of temperature) has been applied to evaluate the effective fluence of each line of CT specimens, from the initial fluence measured in the middle of the rod. This correction is based on the following irradiation embrittlement prediction $(\Delta \mathrm{TT})$ formula described in $[6]$ :

$$
\Delta \mathrm{TT}=15.4 *\left[1+35.7 *(\mathrm{P}-0.008)+6.6 *(\mathrm{Cu}-0.08)+5.8 * \mathrm{Ni}^{2} * \mathrm{Cu}\right] * \Phi^{0.59}
$$

More details are available in paper [7]. Based on the chemical composition of each material (Plant 1 \& Plant 2), it leads to the following temperature shift :

- for the plant $1 \mathrm{CT} 7$ to $12: \mathrm{T}$ shift $=+8^{\circ} \mathrm{C}$

- for the plant $2 \mathrm{CT} 7$ to $12: \mathrm{T}$ shift $=+8^{\circ} \mathrm{C}$ 


\section{Matrix of the experimental programme}

The matrix of the experimental programme is presented in Table 2. 24 specimens ( $1 / 2$ TCT specimens) are tested, including additional fracture toughness $\mathrm{K}_{\mathrm{Jc}}$ and WPS experiments (including LCF and LCTF cycles).

Table 2. Matrix of the experimental programme.

\begin{tabular}{|c|c|c|c|c|}
\hline Plant & $\begin{array}{c}\mathbf{C T}_{12.5} \\
\mathbf{n}^{\circ}\end{array}$ & $\begin{array}{c}\text { Fluence } \\
\left(10^{19} \mathrm{n} / \mathrm{cm}^{2}\right)\end{array}$ & $\begin{array}{c}\text { T shift } \\
\left({ }^{\circ} \mathrm{C}\right)\end{array}$ & Loading \\
\hline 1 & 1 & 6.5 & 0 & $\mathrm{Kjc}$ \\
\hline 1 & 6 & 6.5 & 0 & $\mathrm{Kjc}$ \\
\hline 1 & 7 & 5 & +8 & $\mathrm{Kjc}$ \\
\hline 1 & 12 & 5 & +8 & $\mathrm{Kjc}$ \\
\hline 1 & 2 & 6.5 & 0 & LCF \\
\hline 1 & 3 & 6.5 & 0 & LCF \\
\hline 1 & 4 & 6.5 & 0 & LCF \\
\hline 1 & 5 & 6.5 & 0 & LCF \\
\hline 1 & 8 & 5 & +8 & LCTF \\
\hline 1 & 9 & 5 & +8 & LCTF \\
\hline 1 & 10 & 5 & +8 & LCTF \\
\hline 1 & 11 & 5 & +8 & LCTF \\
\hline 2 & 1 & 6.5 & 0 & $\mathrm{Kjc}$ \\
\hline 2 & 4 & 6.5 & 0 & $\mathrm{Kjc}$ \\
\hline 2 & 6 & 6.5 & 0 & $\mathrm{Kjc}$ \\
\hline 2 & 7 & 5 & +8 & $\mathrm{Kjc}$ \\
\hline 2 & 9 & 5 & +8 & $\mathrm{Kjc}$ \\
\hline 2 & 12 & 5 & +8 & $\mathrm{Kjc}$ \\
\hline 2 & 2 & 6.5 & 0 & LCF \\
\hline 2 & 3 & 6.5 & 0 & LCF \\
\hline 2 & 5 & 6.5 & 0 & LCF \\
\hline 2 & 8 & 5 & +8 & LCTF \\
\hline 2 & 10 & 5 & +8 & LCTF \\
\hline 2 & 11 & 5 & +8 & LCTF \\
\hline
\end{tabular}

\section{Determination of $K_{J c}$ fracture toughness (including $T_{0}$ evaluation)}

First estimation of $\mathrm{T}_{0}$ corresponding to each plant is based on the results of tests made on the original CT12.5 contained in the irradiation capsules (Table 3) :

Table 3. Original determination of $\mathrm{T}_{0}$ on two materials.

\begin{tabular}{|c|c|c|}
\hline Plant & Fluence $\left(10^{19} \mathrm{n} / \mathrm{cm}^{2}\right)$ & $\mathbf{T}_{\mathbf{0}}\left({ }^{\circ} \mathrm{C}\right)$ \\
\hline 1 & 6.60 & $-76 \pm 8.65$ \\
\hline 2 & 6.95 & $-15 \pm 6.95$ \\
\hline
\end{tabular}

To be more precise, additional toughness tests have been performed on 10 CT12.5 machined from the bending rod. The use of CT12.5 needs to make a scale correction to have a "standard" toughness $\mathrm{K}_{\mathrm{jc}} 1 \mathrm{~T}$ in accordance with ASTM E1921-08a standard [4] :

$$
K_{j c(25.4 m m)}=20+\left(K_{j c(12.5 m m)}-20\right) \times\left(\frac{12.5}{25.4}\right)^{0.25}
$$

The corresponding results are given in the Table 4. Among the 10 tests, only 6 tests have been taken into account for final estimation of $\mathrm{T}_{0}$, due to 4 invalid pre-cracking. 
Table 4. Fracture toughness tests on CT12.5 specimens.

\begin{tabular}{|c|c|c|c|c|c|}
\hline Plant $\mathbf{n}^{\circ}$ & $\begin{array}{c}\mathbf{C T} \\
\mathbf{n}^{\circ}\end{array}$ & $\begin{array}{c}\text { Test T } \\
\left({ }^{\circ} \mathbf{C}\right)\end{array}$ & $\begin{array}{c}\text { Fluence } \\
\left(\mathbf{1 0}^{19} \mathbf{n} / \mathbf{c m}^{\mathbf{2}}\right)\end{array}$ & $\begin{array}{c}\text { Corrected } \\
\mathbf{T}\left({ }^{\circ} \mathbf{C}\right)\end{array}$ & $\begin{array}{c}\mathbf{K}_{\mathrm{jc}} \mathbf{1 T} \\
\left(\mathbf{M P a}^{\mathbf{1 / 2}} \mathbf{)}\right.\end{array}$ \\
\hline 1 & 1 & -120 & 6.5 & -120 & invalid \\
\hline 1 & 6 & -120 & 6.5 & -120 & invalid \\
\hline 1 & 7 & -130 & 5 & -122 & 39 \\
\hline 1 & 12 & -130 & 5 & -122 & 54 \\
\hline 2 & 1 & -70 & 6.5 & -70 & invalid \\
\hline 2 & 4 & -78 & 6.5 & $-78\left(^{*}\right)$ & 57 \\
\hline 2 & 6 & -70 & 6.5 & -70 & invalid \\
\hline 2 & 7 & -70 & 5 & -62 & 69 \\
\hline 2 & 9 & -88 & 5 & $-80\left(^{*}\right)$ & 44 \\
\hline 2 & 12 & -70 & 5 & -62 & 88 \\
\hline
\end{tabular}

(*) For plant $2 \mathrm{CT} n^{\circ} 4$ and 9, test temperature is below $T_{0}-50^{\circ} \mathrm{C}\left(-72^{\circ} \mathrm{C}-\right.$ see forward) but all the complementary tests have been made to refine $T_{0}$ calculations and also to have test results at low temperatures which were judged better than to have only Master Curve values

To take into account the results of the tests made on the CT12.5 contained in the irradiation capsules with these results, a temperature correction has been applied because of the difference of fluence compared to the first line of CT12.5. The corrected temperatures are given in Table 5, with the corresponding final $\mathrm{T}_{0}$ values :

Table 5. Final determination of $\mathrm{T}_{0}$ on two materials.

\begin{tabular}{|c|c|c|c|}
\hline Plant $n^{\circ}$ & Fluence $\left(10^{19} \mathrm{n} / \mathrm{cm}^{2}\right)$ & Test T $\left({ }^{\circ} \mathrm{C}\right)$ & Corr. T $\left({ }^{\circ} \mathrm{C}\right)$ \\
\hline 1 & 6.60 & -60 & -62 \\
\hline 2 & 6.95 & -40 & -40 \\
\hline 2 & 6.95 & -10 & -10 \\
\hline & Plant & $\mathrm{T}_{0}\left({ }^{\circ} \mathrm{C}\right)$ & \\
\hline & 1 & $75 \pm 7.76$ & \\
\hline & 2 & $22 \pm 7.17$ & \\
\hline
\end{tabular}

The fracture toughness $\mathrm{K}_{\mathrm{Jc}}$ properties of both materials (Plant $1 \&$ Plant 2), derived from $\mathrm{T}_{0}$ determination, are illustrated on Figure 3.
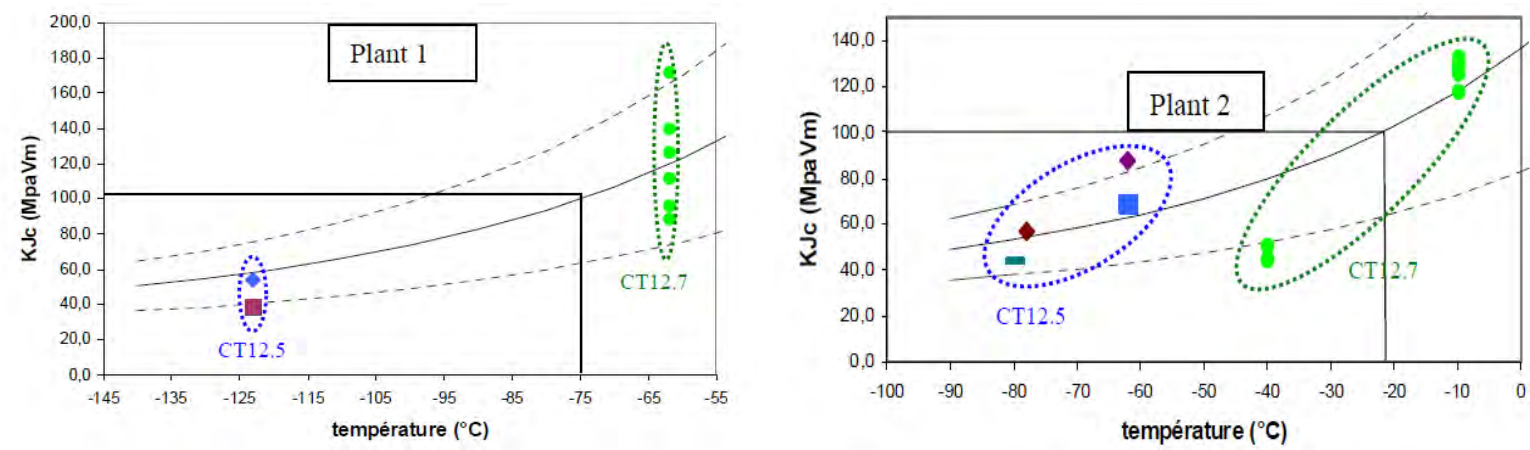

Figure 3. Fracture toughness $\mathrm{K}_{\mathrm{Jc}}$ for two materials (Plants $1 \& 2$ ).

\section{Definition of WPS loading paths}

The objective of the programme is to conduct some WPS experiments in loading conditions representative of real PTS event (and more particularly the level of initial preloading $\mathrm{K}_{\mathrm{wps}}$ ). Two WPS 
laoding paths have been finally taken into account (Table 2), some LCF cycles (Load-Cooling-Fracture with constant loading during the cooling) and some LCTF cycles (Load-Cooling-Transient-Fracture with decreasing loading during the cooling), illustrated on Figure 4 :
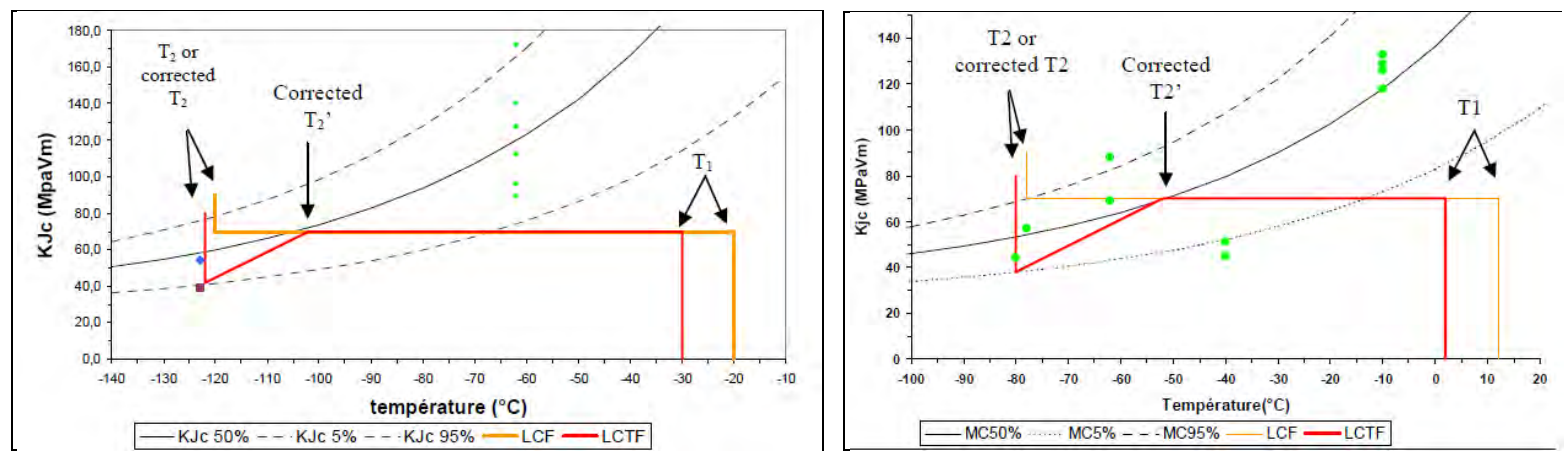

Figure 4. Schematic of WPS loading paths (LCF \& LCTF cycles)

\section{MAIN EXPERIMENTAL RESULTS}

\section{Tensile tests on TC specimens}

4 Tensile tests have been made at four temperatures on the 2 surveillance capsules materials to check the toughness tests validity and to be used for numerical simulation studies. The results are given in Table 6 and Figure 5.

Table 6 : Tensile tests on TC specimens.

\begin{tabular}{|c|c|c|c|c|c|c|c|c|}
\hline Plant & $\begin{array}{c}\mathrm{T} \\
\left({ }^{\circ} \mathrm{C}\right)\end{array}$ & $\begin{array}{c}\text { Fluence } \\
\left(10^{19} \mathrm{n} / \mathrm{cm}^{2}\right)\end{array}$ & $\begin{array}{c}\text { Section } \\
\left(\mathrm{mm}^{2}\right)\end{array}$ & $\begin{array}{c}\mathbf{R p}_{0,2} \\
(\mathrm{MPa})\end{array}$ & $\begin{array}{c}\mathbf{R m} \\
(\mathrm{MPa})\end{array}$ & $\begin{array}{c}\mathbf{A} \\
(\%)\end{array}$ & $\begin{array}{c}\mathbf{Z} \\
(\%)\end{array}$ & $\begin{array}{c}\mathbf{E} \\
(\mathrm{MPa})\end{array}$ \\
\hline 1 & -20 & 5,93 & 31,619 & 590 & 700 & 29 & 71 & 195871 \\
\hline 1 & -120 & 6,05 & 31,649 & 755 & 821 & 27 & 66 & 186802 \\
\hline 2 & 23 & 5,96 & 31,649 & 572 & 680 & 28 & 75 & 193212 \\
\hline 2 & -78 & 6,08 & 31,646 & 682 & 792 & 28 & 67 & 185233 \\
\hline
\end{tabular}

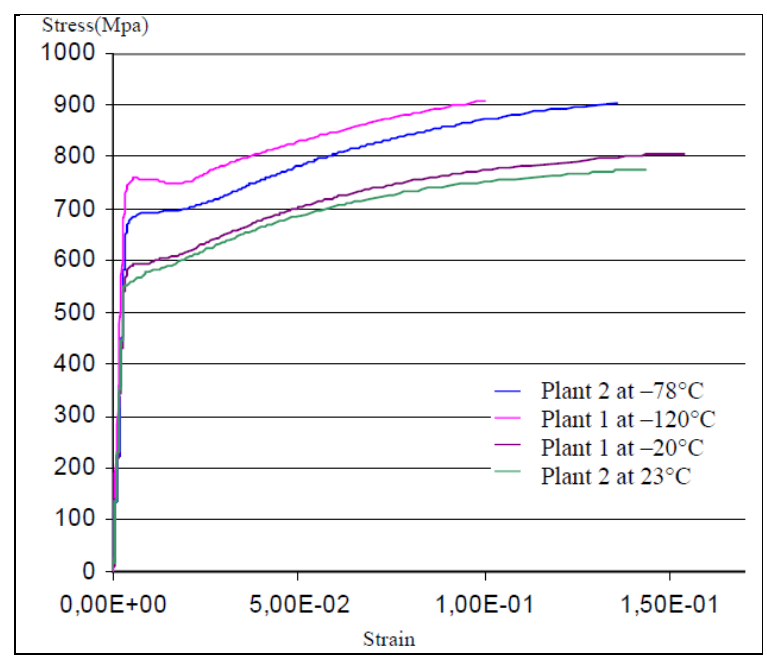

Figure 5. Tensile tets on TC specimens. 


\section{Main WPS experimental results}

Based on the matrix defined in Table 2, 14 WPS experiments have been conducted with full success, summarized (with main experimental conditions) in Table 7 and on Figure 6 (Plant 1) and Figure 7 (Plant 2). More details are available in paper [7].

Table 7. Loading conditions and results (WPS experiments).

\begin{tabular}{|c|c|c|c|c|c|c|c|c|c|c|}
\hline Plant & CT & $\begin{array}{l}\text { WPS } \\
\text { cycle }\end{array}$ & $\begin{array}{c}\text { Fluence } \\
\left(10^{19}\right. \\
\left.\mathrm{n} / \mathrm{cm}^{2}\right)\end{array}$ & $\begin{array}{l}\text { Pre-stress } \\
\left(\mathrm{MPa} \cdot \mathrm{m}^{1 / 2}\right)\end{array}$ & $\begin{array}{c}\text { Intermediate } \\
\text { stress } \\
\left(\mathrm{MPa} \cdot \mathrm{m}^{1 / 2}\right)\end{array}$ & $\begin{array}{l}\text { T1 } \\
\left({ }^{\circ} \mathrm{C}\right)\end{array}$ & $\begin{array}{c}\text { Corr.T2' } \\
\left({ }^{\circ} \mathrm{C}\right)\end{array}$ & $\begin{array}{c}\mathrm{T} 2 \\
\left({ }^{\circ} \mathrm{C}\right)\end{array}$ & Corr. T2 $\left({ }^{\circ} \mathrm{C}\right)$ & $\begin{array}{c}\text { Effective } \\
\text { toughness } \\
\mathrm{K}_{\mathrm{Jc}} 1 \mathrm{~T} \\
\left(\mathrm{MPa} \cdot \mathrm{m}^{1 / 2}\right)\end{array}$ \\
\hline 1 & 2 & LCF & 6,5 & 70 & 1 & -20 & 1 & -120 & -120 & 78 \\
\hline 1 & 3 & LCF & 6,5 & 70 & 1 & -20 & 1 & -120 & -120 & 80 \\
\hline 1 & 4 & LCF & 6,5 & 75 & 1 & -20 & 1 & -120 & -120 & 86 \\
\hline 1 & 5 & LCF & 6,5 & 75 & 1 & -20 & 1 & -120 & -120 & 85 \\
\hline 1 & 8 & LCTF & 5,0 & 70 & 42 & -30 & -102 & -130 & -122 & 83 \\
\hline 1 & 9 & LCTF & 5,0 & 70 & 42 & -30 & -102 & -130 & -122 & 81 \\
\hline 1 & 10 & LCTF & 5,0 & 75 & 42 & -30 & -102 & -130 & -122 & 82 \\
\hline 1 & 11 & LCTF & 5,0 & 75 & 42 & -30 & -102 & -130 & -122 & 79 \\
\hline 2 & 2 & LCF & 6,5 & 70 & I & 12 & I & -78 & -78 & 87 \\
\hline 2 & 3 & LCF & 6,5 & 70 & 1 & 12 & 1 & -78 & -78 & 91 \\
\hline 2 & 5 & LCF & 6,5 & 70 & 1 & 12 & 1 & -85 & -85 & 92 \\
\hline 2 & 8 & LCTF & 5,0 & 70 & 38 & 2 & -52 & -88 & -80 & 98 \\
\hline 2 & 10 & LCTF & 5,0 & 70 & 38 & 2 & -52 & -88 & -80 & 76 \\
\hline 2 & 11 & LCTF & 5,0 & 70 & 38 & 2 & -52 & -88 & -80 & 81 \\
\hline
\end{tabular}

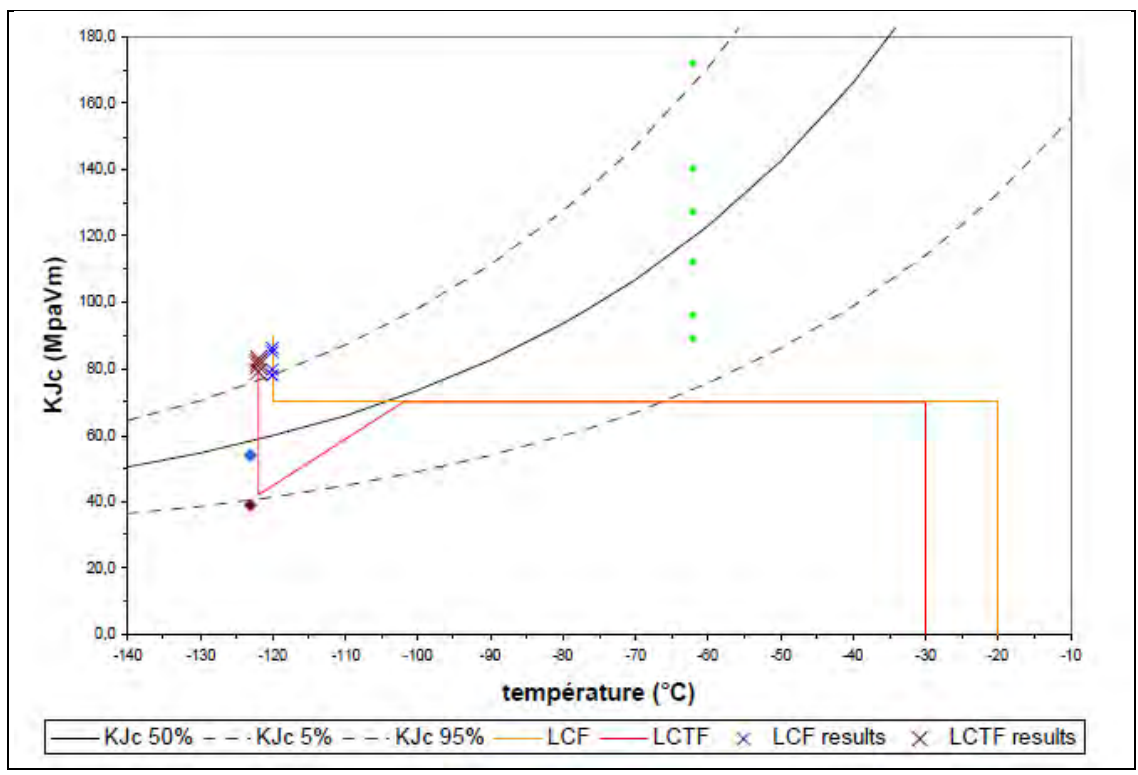

Figure 6. WPS results on Plant 1 (LCF \& LCTF WPS cycles). 


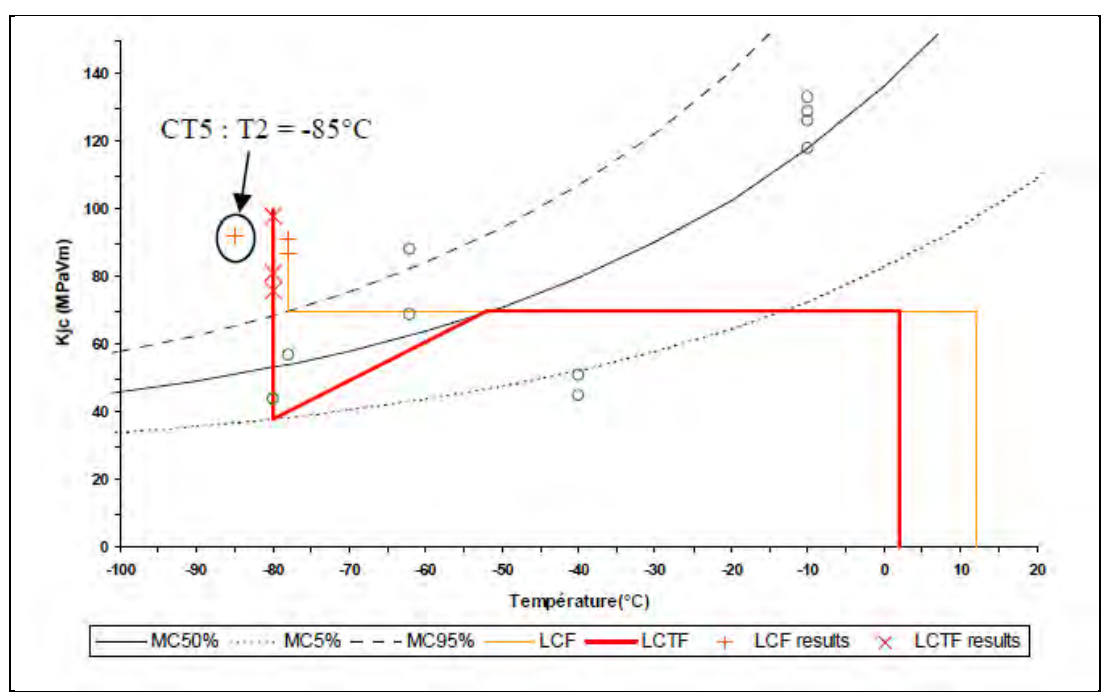

Figure 7. WPS results on Plant 2 (LCF \& LCTF WPS cycles).

A similar programme, conducted by EDF in 2003 on representative RPV steels, dedicated to applicability of WPS effect to irradiated materials had already shown the validity of the WPS effect in such conditions [8]. These new results, obtained on more highly irradiated RPV materials, clearly confirm these observations :

- there is no brittle failure initiation during the cooling phase of the WPS loading path, with constant load (LCF cycle) or decreasing load (LCTF cycle), even if the $\mathrm{K}_{\mathrm{J}}$ loading curve crosses the $\mathrm{K}_{\mathrm{Ic}}$ scatter band

- an increase of the effective fracture toughness is observed during the final reloading at low temperature, compared to the initial fracture toughness $\mathrm{K}_{\mathrm{Ic}}$, sometimes very significant (e.g. ratios $\mathrm{K}_{\text {fract }} / \mathrm{K}_{\mathrm{Ic}}, \mathrm{K}_{\text {fract }} / \mathrm{K}_{\mathrm{wps}}$ )

These new results clearly confirm the validity of the WPS effect on the fracture resistance of the RPV highly irradiated steels, already shown in a wide panel of experimental conditions (materials, specimens and geometries, loadings ...) [1][2][3]. There is no specific effect of irradiation on this concept.

\section{INTERPRETATION OF WPS EXPERIMENTS}

\section{Analyses based on WPS analytical models}

Some WPS analytical models are available. Based on a few input data (some experimental parameters, e.g. the level of preloading $\mathrm{K}_{\mathrm{WPS}}$, the magnitude $\Delta \mathrm{K}_{\mathrm{u}}$ of unloading, the level of loading after unloading $\mathrm{K}_{2}$, the original fracture toughness of the material $\mathrm{K}_{\text {mat }}$ at the fracture temperature $\mathrm{T}_{2}$ ), these models allow an easy evaluation of final level of fracture $\mathrm{K}_{\text {fract }}$ during the final reloading of the specimen, taking into account the effect of load history on the fracture resistance of the material. Four analytical WPS engineering models have been used, described in corresponding references (with conditions of validity) :

- $\quad$ The Chell \& Haigh WPS model, derived from original Chell WPS model [9][10] :

$$
\circ \mathrm{K}_{\text {fract }}=\mathrm{K}_{2}+0.2 \Delta \mathrm{K}_{\mathrm{u}}+0.87 \mathrm{~K}_{\mathrm{mat}}
$$

- The original Wallin WPS model proposed by K. Wallin [5] :

$$
\circ \mathrm{K}_{\text {fract }}=\mathrm{K}_{2}+\left(\mathrm{K}_{\text {mat }} \cdot \Delta \mathrm{K}_{\mathrm{u}}\right)^{0.5}+0.15 \mathrm{~K}_{\text {mat }}
$$


- $\quad$ The WPS model proposed by NRI, derived from Wallin WPS model [3] :

$\circ \quad \mathrm{K}_{\text {fract }}=\mathrm{K}_{2}+\left(\mathrm{K}_{\mathrm{mat}} \cdot \Delta \mathrm{K}_{\mathrm{u}}\right)^{0.5}$

- A new WPS model (ACE) developed in France by S. Chapuliot [11] [12] :

$\circ \quad \mathrm{K}_{\text {fract }}=\max \left[\mathrm{K}_{\mathrm{mat}}(\mathrm{T}) ; \min \left(\mathrm{K}_{\mathrm{WPS}} ; \mathrm{K}_{2}+\mathrm{K}_{\mathrm{wps}} / 2\right)\right]$

These predictions are generally in good agreement with the experimental observations, even sometimes too conservative (Figure 8). These results confirm similar observations made on other WPS experimental experiments [3][13].

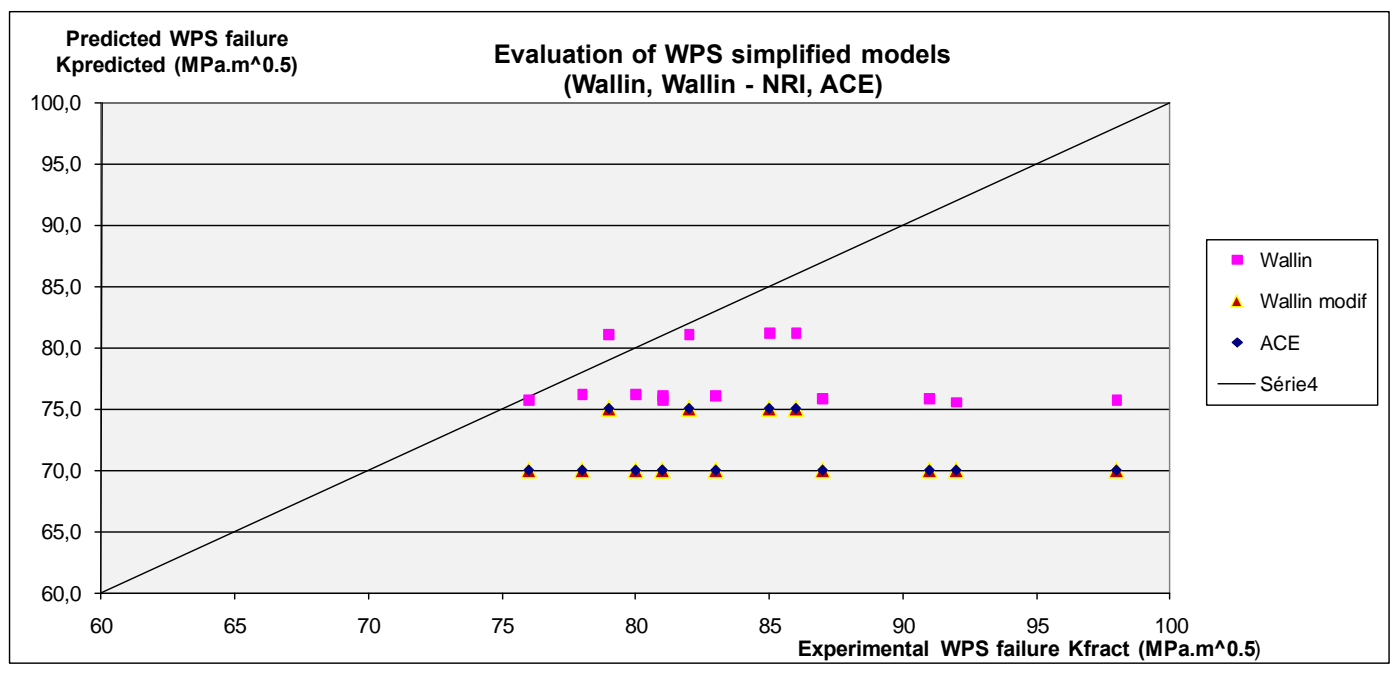

Figure 8. Example of tests interpretation with WPS simplified models (Wallin, Wallin-NRI, ACE).

In addition to the use of analytical models, more refined analyses are performed including :

- The refined evaluation of the stress intensity factor $\mathrm{K}_{\mathrm{J}}$ based on $2 \mathrm{D}$ elastic-plastic finite element computations

- The use of local approach to cleavage fracture (through the modified Beremin model [14] derived from original Beremin model). More particularly, it allows the evaluation of the brittle failure probably of a specimen (or a component) under complex loading, such a WPS loading path :

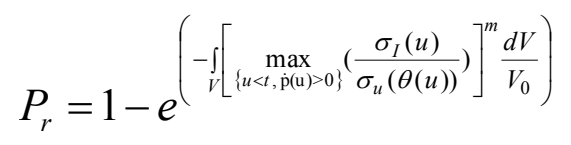

This approach requires the identification of two specific parameters $-\mathrm{m}$ and $\sigma_{\mathrm{u}}-$ for the considered materials. An illustration of such an approach is given on Figure 9 for one of the tested material submitted to WPS LCF and LCTF loading paths. It clearly shows :

- The effect of the load history on the brittle fracture of the specimens, by comparing the predicted failure probability of WPS specimens to isothermal CT specimens (without any prior loading)

- The capability of the model to predict the failure of the specimens, by comparing the predicted failure probability of WPS specimens to experimental results (with the corresponding scatter band), even if the level of accuracy could be improved 

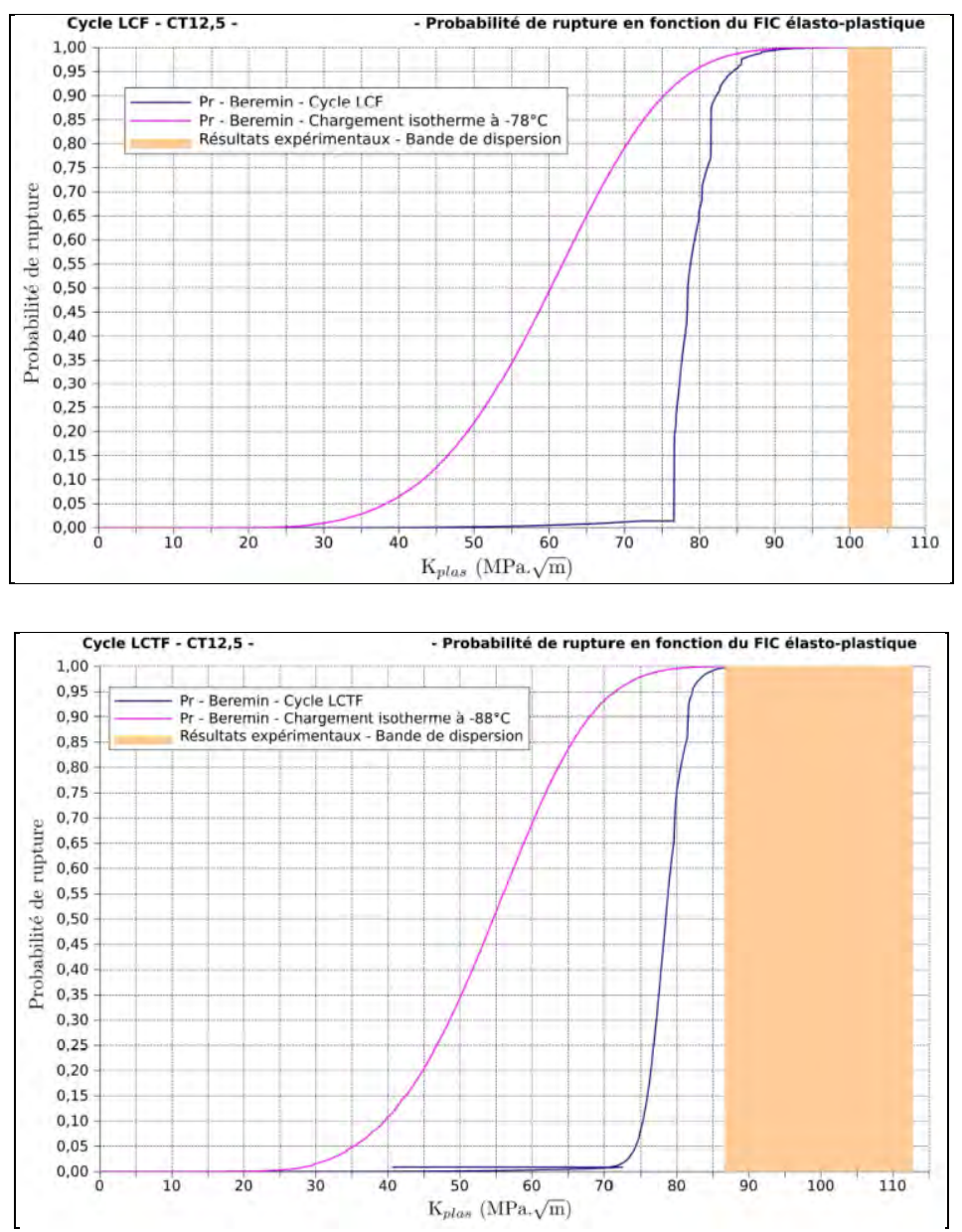

Figure 9. Example of interpretation with local approach to fracture (LCF \& LCTF WPS cycles).

\section{CONCLUSION AND PERSPECTIVES}

Experimental tests performed on two highly irradiated RPV steels at a 40 years equivalent fluence $(\Phi \sim$ $\left.6,5.10^{19} \mathrm{n} / \mathrm{cm}^{2}\right)$ have confirmed previous results obtained in 2003 for a 30 years equivalent fluence $(\Phi \sim$ $4,6.10^{19} \mathrm{n} / \mathrm{cm}^{2}$ ) and again demonstrate the validity of WPS on highly irradiated RPV materials.

For the two studied load paths, the validity and applicability of the warm pre-stress effect on highly RPV irradiated materials has been fully confirmed:

- there is no brittle failure initiation during the cooling phase of the WPS loading path, with constant load (LCF cycle) or decreasing load (LCTF cycle), even if the $\mathrm{K}_{\mathrm{J}}$ loading curve crosses the $\mathrm{K}_{\mathrm{Ic}}$ scatter band

- an increase of the effective fracture toughness is observed during the final reloading at low temperature, compared to the initial fracture toughness $\mathrm{K}_{\mathrm{Ic}}$, sometimes very significant

These new results clearly confirm the validity of the WPS effect on the fracture resistance of the RPV steels, already shown in a wide panel of experimental conditions (materials, specimens and geometries, loadings ...). There is no specific effect of irradiation on this concept.

Several WPS analytical models have been applied to experimental data collected during these two test series. Conservatism of these models has been demonstrated for two irradiated RPV steels at a 40 years equivalent fluence. Numerical analysis of these experimental data, using rational data from tensile tests, have been conducted and confirm robustness of experimental data obtained. 


\section{ACKNOWLEDGMENTS}

The authors thank H. Churier-Bossennec (EDF SEPTEN) and C. Pagès (EDF UNIE) for their technical and financial support to this project. A particular thank to G. Chas in charge of the experimental programme and now retired.

\section{REFERENCES}

[1] D. Moinereau, ,Bilan des études sur le pré-chargement à chaud et sa prise en compte dans l'analyse des marges des cuves REP vis-à-vis de la rupture fragileec, EDF report HT26/05/047A.

[2] D. Moinereau, ,Pré-chargement à chaud - Synthèse des essais effectués au MPA Stuttgart sur des aciers du type 18 MND5 et 16 MND5 $^{\text {ee }}$ EDF report HT-26/00/026A.

[3] D. Moinereau, S. Chapuliot, S. Marie, C. Jacquemoud, „NESC VII project : a European project for application of WPS in RPV assessment including biaxial loadingee, SMIRT 22 Conference, 18-23 August 2013, San Francisco, USA.

[4] ASTM E1921-08a, ,Standard Test Method for Determination of a Reference Temperature, $\mathrm{T}_{0}$ for Ferritic Steels in the Transition Range ${ }^{e e}$.

[5] K. Wallin, „Master Curve implementation of the warm pre-effecte, Engineering Fracture Mechanics, $\mathrm{n}^{\circ} 70$.

[6] P. Todeschini, Y. Lefevre, H. Churier-Bossennec, N. Rupa, G. Chas, C. Benhamou, „Revision of the irradiation embrittlement correlation used for the EDF RPV fleet", International symposium Fontevraud 7, ,Contribution of the materials investigations to improve the safety and performance of LWRs"e, Avignon, 26-30 September 2010.

[7] G. Chas, E. Molinié, E. Garbay, F. Clemendot, D. Moinereau, H. Churier-Bossennec, C. Pagés, ,Fracture toughness of a highly irradiated pressure vessel steel in warm pre-stress loading conditions"e, ASME PVP 2011 Conference, 17-21 July 2011, Baltimore, USA

[8] D. Moinereau, A. Dahl, G. Chas, N. Rupa, J. Bourgoin, H. Churier-Bossennec, „Application of Warm pre-stress to RPV assessment ${ }^{e c}$, International symposium Fontevraud 6, „Contribution of materials investigations to improve the safety and performance of LWRs , Fontevraud, September 2006.

[9] R6 - Revision 4, Chapter III, Section III-10, Load History Effects.

[10] G.G. Chell, J.R. Haigh, „The effect of warm pre-stressing on proof tested pressure vessels"e International Journal of Pressure Vessel and Piping, 23, 121-132.

[11] S. Chapuliot, „WPS criterion proposition based on experimental data base interpretation “, Nordic Symposium, 25/26 ${ }^{\text {th }}$ November 2009, Stockholm.

[12] S. Chapuliot, J.P. Izard, D. Moinereau, S. Marie, „WPS criterion proposition based on experimental data base interpretation", International symposium Fontevraud 7, „Contribution of the materials investigations to improve the safety and performance of LWRs"e, Avignon, 26-30 September 2010.

[13] C. Jacquemoud, T. Yuritzinn, S. Marie, S. Chapuliot, D. Moinereau, M. Nedelec, ,Synthesis of the NESC VII European project: demonstration of warm pre-stressing effect in biaxial loading conditions, ASME PVP 2013, 14-18 July 2013, Paris, France.

[14] W. Lefevre, R. Masson, ,A modified Beremin model to simulate the warm pre-stress effecte, International Journal of Pressure Vessel and Piping, 23, 121-132. 